\title{
Heavy metal concentration in horseshoe crab (Carcinoscorpius rotundicauda and Tachypleus gigas) eggs from Malaysian coastline
}

\begin{abstract}
The level of trace elements $(\mathrm{Cu}, \mathrm{Zn}, \mathrm{Fe}, \mathrm{Ni}, \mathrm{Pb}$, and $\mathrm{Cd})$ was measured in eggs of horseshoe crabs, Carcinoscorpius rotundicauda, and Tachypleus gigas, from Malaysia. The concentrations ( $\varepsilon \mathrm{g} / \mathrm{g}$ wet weight) of these elements in C. rotundicauda eggs ranged from 18.84 to 65.44 for $\mathrm{Cu}, 34.65$ to 104.08 for $\mathrm{Zn}, 4.497$ to 75.95 for $\mathrm{Fe}, 1.88$ to 11.17 for $\mathrm{Ni}$, 0.52 to 3.64 for $\mathrm{Cd}$, and non-detectable for $\mathrm{Pb}$. The level of these elements in $\mathrm{T}$. gigas eggs was from 30.54 to 120.32 for $\mathrm{Cu}, 46.34$ to 88.96 for $\mathrm{Zn}, 21.88$ to 88.96 for Fe, 4.71 to 7.82 for $\mathrm{Ni}, 0.02$ to 4.11 for $\mathrm{Cd}$, and 10.00 to $25.84 \mathrm{for} \mathrm{Pb}$. C. rotundicauda eggs showed significantly higher amounts of trace elements except for $\mathrm{Ni}$ and $\mathrm{Cd}$. The heavy metals analyzed were higher than the range of permissible limit for human consumption.
\end{abstract}

Keyword: Horseshoe crab eggs; Heavy metal 